\title{
SOBRE EL MÉTODO DE LA FILOSOFÍA
}

1. Más de una vez me he preguntado en qué consiste el empeño fundamental del filósofo: quiero decir aquel empeño que constituye su cuestión de honor, su razón de ser como filósofo. Puede parecer que sea fácil la respuesta: tal empeño está en confrontarse con la "Verdad". Pero prescindiendo aquí de la pregunta de Pilatos, que en el acto se presentaría en los labios, y sin ceder a demasiado fáciles consideraciones escépticas, diré que la noción de verdad es demasiado augusta, alta y lejana para poder ser el término del empeño en un trabajo eficaz, como el del investigador filosófico; cuyo horizonte está limitado, como el horizonte de cualquier otro investigador, por un complejo de condiciones que obran ya como estímulos, ya como impedimentos de su actividad. El empeño del filósofo debe encontrar su término en este horizonte para ser efectivo e imperativo; de otra suerte, corre por su naturaleza genérica el riesgo de no empeñar en nada, ya que bajo el nombre de la Verdad puede admitirse o permitirse cualquier cosa. En el carácter cotidiano, limitado, pero efectivo e imperativo del empeño filosófico, jamás se podría insistir bastante. Permitid que lo haga con un apólogo. Imaginemos que en un grupo de gente que viva intercambiando servicios y bienes en especie haya un hombre que posea una gran cantidad de oro. Imaginemos que este hombre predique a los demás que la única riqueza es el oro, y que por ello se declare el único rico, el único inteligente y sabio, considerando cón desprecio a los demás, que se fatigan haciendo sus pobres intercambios. Claro es que este hombre no sólo será más una molestia que una ayuda para los demás, sino que también estará destinado a morir de hambre, al no ser su oro intercambiable por bienes o servicios utilizables.

Pero supongamos que en vez de predicar que el oro es la única riqueza, este hombre se mezcle con los demás, participe en sus trabajos e intercambios, y haga ver cómo el uso del oro por moneda puede facilitar y mejorar las relaciones económicas de la comunidad en que vive. En este segundo caso, se habrá empeñado, ya no en confrontarse con la que creía y era para él la verdad, sino en confrontarse con algo más limitado, pero más eficaz: un cierto método de cambio; y se habrá empeñado en él con su actividad cotidiana, uniéndose a los demás hombres en el trabajo común. Este es el apólogo. Ahora, yo no digo que los filósofos hayan sido frecuentemente semejantes al personaje ficticio que predica la verdad de que el oro es la única riqueza a una comunidad que vive de intercambios en especie. Sólo digo que ésta ha sido y es una tentación del filósofo, tentación pasada y presente, de que es mejor librarse, para tomarse, en cambio, 
el camino modesto, pero más eficaz, de los que, sabiendo bien vivir con los demás y entre los demás, se limitan a proponer alguna nueva técnica de vivir, esto es, algún nuevo método de pensar, de obrar y de sentir (comoquiera que se entiendan estas palabras): nuevo no en sentido absoluto, sino respecto de la situación que se trata de corregir. Consideraciones de esta especie persuaden a fijar la atención en las técnicas, esto es, en los métodos, de la investigación, más que en la "verdad". La propuesta de una verdad es cosa de tomarla o dejarla: un método, para juzgarlo, debe ponerse a prueba activamente por cada uno y puede corregirse o mejorarse. Alguna vez ha acaecido, en el curso de la historia de la filosofía, que se le impusiera a un filósofo la necesidad de abjurar de su "verdad" en nombre de otra "verdad". También ha acaecido que el filósofo se rehusara y sufriese las consecuencias de ello. Pero si en vez de imponer al filósofo otra "verdad", se le muestra que el método empleado por él no conduce a aquel resultado que él cree verdad, o que el método mismo debe rectificarse de algún modo, no tiene el filósofo, en principio, ninguna objeción para abandonar su "verdad". Y es cuanto en realidad ha hecho más o menos cualquier filósofo en el curso de su vida, modificando o corrigiendo sus concepciones bajo la presión de críticas propias o ajenas, o de circunstancias o hechos de cualquier naturaleza. Esta observación hace evidente la naturaleza del empeño filosófico, y en general del empeño propio de cualquier investigación racional. La tragedia de Galileo no se habría producido, si Galileo hubiera podido convencerse, basándose en los métodos que estimaba válidos para la investigación, de que era falsa la teoría copernicana. El "empeñarse con la verdad" es en realidad, en todos los casos, el empeñarse en un método específico de investigación.

2. Las consideraciones precedentes y la conclusión a que conducen pueden expresarse de nuevo en otra forma, diciendo que el proponer algo como "verdad" implica en todos los casos el proponer, explícita o implícitamente, un método en virtud del cual puede atestiguarse y controlarse la "verdad" propuesta. Estimo que esta regla es de la mayor importancia tanto para la ciencia cuanto para la filosofía, y en general para todo tipo, forma o especie de investigación racional. No intento aquí sostener que haya o pueda haber un único método para todas las ciencias y disciplinas, ni sostengo la tesis contraria, de la diversidad irreducible de los métodos. Dejamos por un momento en suspenso este problema. No puedo ni siquiera detenerme a discutir la regla propuesta en lo que concierne a la ciencia, respecto de la cual creo, sin embargo, que fácilmente puede mostäarse que tal regla se ha hecho valer, desde Galileo hasta hoy, cada vez con mayor rigor. Intento simplemente afirmar que si se habla de "verdad" en un sentido distinto del de la imposición autoritaria y la creencia personal 
gratuita, se supone constantemente que hay un método por el cual puede cualquiera, de algún modo $\mathrm{y}$ en alguna medida, atestiguar o controlar la verdad misma. Un método no es necesariamente una serie compleja de operaciones y cálculos dirigidos por reglas explícitas. Siempre es, empero, una operación, incluso cuando es relativamente simple o está enteramente confiada a una estructura orgánica, y es una operación repetible: si, por ejemplo, digo "la lámpara está sobre la mesa", afirmando esta proposición como verdad, doy por supuesto que cualquiera que esté en posesión de un órgano visual normal puede atestiguar la proposición en cuestión, y puede eventualmente controlarla mediante el uso del tacto. Puede, naturalmente, admitirse que existan "verdades evidentes", esto es, verdades que se juzgan tales de un golpe de vista o que resultan tales por la simple disposición de las palabras. Pero en este caso se ha recurrido simplemente a un método particular, que es el de la evidencia, el cual, como sabemos desde Descartes, no es ciertamente el más fácil de usar e implica numerosos problemas de lógica. No podemos ni siquiera ignorar que muchas filosofías racionalistas, antiguas y recientes, se valen de la deducción para conferir valor a sus afirmaciones; pero la deducción es en todos los casos un procedimiento metódico en el que las distintas proposiciones sólo adquieren valor de verdad en virtud del orden en que se deriva una de otra. Sea el método obvio, fácil y esté ligado al dinamismo de la percepción (pero de este dinamismo demuestra la psicología moderna toda la complejidad de estructura), o sea difícil de emplear y esté compuesto de operaciones que sólo pueda seguir quien tenga una competencia y un adiestramiento especiales - resulta constante la regla de que la aserción de una verdad, en cualquier campo y a cualquier nivel de la investigación racional, implica el uso de un método adecuado, esto es, de una técnica de testimonio y de control.

Las palabras "método de testimonio y de control" requieren algún esclarecimiento. Obviamente, no se refieren tan sólo a técnicas que permiten pruebas irrefutables o demostraciones apodícticas, aunque también comprendan tales técnicas como casos límites o privilegiados que pueden verificarse en determinados campos de la investigación racional. Ni siquiera se refieren exclusivamente a la verificación empirica tal como se la entiende por la tradición empirista (como un recurrir a los datos sensibles que emergen de la experiencia) o por la ciencia. Deben tomarse en una significación más extensa y comprensiva, como incluyendo el recurrir a todo tipo o especie de indicio, indicación, signo, testimonio, prueba, demostración, con la sola restricción de que tal recurrir sea, en adecuadas circunstancias, repetible, esto es, controlable. La significación restringida y rigurosa de las técnicas de verificación, de confirmación y de control, como se encuentran en el ámbito de disciplinas específicas, junto a un alto grado de madurez científica, no está excluída de la expresión que he empleado, 
pero sólo comprende, evidentemente, pequeñas zonas del extenso ámbito cubierto por ella; ya que la regla propuesta se presupone válida de toda proposición, incluso la más banal, que pretenda afirmar una verdad cualquiera. Las innumerables proposiciones de que está hecho nuestro discurso vulgar en torno a situaciones o asuntos de cualquier género, importantes, o menos importantes o insignificantes, siempre están sostenidas por el posible recurrir a técnicas de testimonio, todo lo simples o primitivas que se quiera, $\mathrm{y}$, sin embargo, grosso modo, adecuadas. Con frecuencia son tales técnicas sólo simples y primitivas a primera vista, mientras que un análisis riguroso puede descubrir en ellas una rica complejidad de operaciones vueltas fáciles o expeditas tan sólo por las estructuras biológicas, psicológicas o sociológicas dominantes. - ¿Dónde está Pedro?” —“Está en el cuarto de al lado. Lo he visto hace un momento." Lo que significa: cualquiera hubiese pudido verlo en el cuarto de al lado hace un momento -esto es, el recurrir a una técnica de testimonio. Pero todos sabemos, y lo saben especialmente los juristas y los historiadores, a qué difíciles problemas puede dar origen el uso de esta técnica. Comoquiera que sea, la regla propuesta se presenta con la máxima generalidad por estar ligada a todas las aserciones de que humanamente quiera darse cuenta. Hay indudablemente aserciones de que no se puede o no se quiere dar cuenta humanamente; pero éstas caen fuera del dominio de la filosofía y, en general, de la investigación racional. Y también es verdad que cuando se quieren justificar o defender de algún modo tales aserciones o exponer sus títulos o derechos de validez, no se hace más que volver a caer bajo la regla expuesta y recurrir a una u otra de las técnicas de testimonio y de control a que se refiere en general tal regla.

3. Por su generalidad puede llamarse la regla expuesta un principio, y, si no hay objeciones, lo llamaré principio metodológico general. Tal principio no permite, al menos a primera vista, discriminación alguna entre filosofía y filosofía. Dada la forma en que lo he enunciado y aquella en que to he ilustrado, puede mostrarse con bastante facilidad que cualquier filosofía (por lo mismo, excluyendo las ocurrencias extravagantes de los aficionados) satisface, en algún modo y medida, el principio mismo. Indudablemente, están con frecuencia las filosofías en el más completo desacuerdo acerca de la técnica metódica adecuada para dar a las proposiciones filosóficas su validez. En esto, se diferencian las filosofías de las disciplinas científicas, en cada una de las cuales está, en cambio, reducido al mínimo el desacuerdo scbre este punto. Pero este desacuerdo no excluye que cada una a su modo respondan a la exigencia encerrada en el principio metodológico. Este principio no permite, por tanto, la crítica negativa de una filosofía con el uso de una técnica de testimonio o de control que ella no haya admitido implícita o explícitamente o que haya negado rotundamente. No puede repro- 
charse a Hegel el no fundar sus aserciones en la técnica de testimonio y de control empleada por Locke; o recíprocamente. Podría hacerse esto, si pudiera establecerse de una vez por todas la unidad de método de la filosofía; pero es claro que toda tentativa de este género ( $y$ la historia de la filosofía es rica en tales tentativas) no hace más que multiplicar los métodos mismos. Esto acaece porque la noción misma de "unidad de método" es una filosofía, hasta una metafísica. Que toda aserción, cualquiera que sea el campo a que pertenezca, debe hacer referencia a algún método adecuado de testimonio y de control -es una exigencia razonable a la que de hecho no se sustrae ninguna filosofía. Pero que todas las aserciones, pertenecientes a todos los campos posibles $\mathrm{y}$, por ende, también a todas las filosofías, puedan y deban recurrir a un único método -es una exigencia completamente diversa que no puede encontrar a su vez justificación metodológica y por lo mismo sólo puede ser el postulado de una filosofía particular. El diferente alcance lógico de las palabras que he subrayado en las dos cláusulas precedentes me dispensa de toda ulterior ilustración de este punto.

El rechazar la noción de "unidad de método" en el dominio de la filosofía no implica, sin embargo, el reconocimiento automático de la pluralidad, heterogeneidad e inconfrontabilidad de los métodos empleados y propuestos por diversas filosofías. En efecto, esta tesis, siendo totalitaria como la simétrica y opuesta, se presenta, exactamente cual ésta, como no susceptible de una justificación adecuada y sólo susceptible de que la postule una filosofía particular. Afortunadamente, con ocasión de análogas circunstancias, han elaborado los lógicos una noción extremadamente fecunda que permite prescindir por completo de las nociones de unidad total y pluralidad radical. Tal noción es la de "familia de conceptos". Los miembros de una misma familia no llevan la contraseña de un único rasgo común, sino de rasgos o caracteres múltiples, de cada uno de los cuales participan sólo pocos miembros, pero el complejo de los cuales constituye un conjunto de relaciones . múltiples que sirven de contraseña, en alguna forma, al grupo familiar. Así, por ejemplo, no todos tendrán la misma nariz o el mismo color del pelo o de los ojos, el mismo modo de andar, de moverse, etc., pero éstas y las demás semejanzas siempre verificables en el grupo, sí harán que pueda reconocerse precisamente en él un grupo familiar. Esta noción es fecunda, porque aunque fuese posible verificar entre todos los miembros de una familia la misma relación, por ejemplo, el color de los ojos o del pelo, no debiera considerarse esta relación como la única capaz de definir el grupo familiar, porque no excluiría las demás que siempre debieran investigarse y sacarse a la luz. Los números, por ejemplo, se consideran hoy como una familia de conceptos, y como familia de conceptos pueden entenderse también los términos "aritmética", "geometría", "cálculo", etc. Análogamente podremos hablar, en el 
campo de la filosofía y respecto del problema que aquí nos interesa, de "familias de métodos", y podremos buscar, en el interior de cada familia y también entre diversas familias, variadas relaciones de concordancia y discordancia, de dependencia o de interdependencia polémica, etc., etc., sin presumir jamás haber agotado, con la verificación de una sola característica, la semejanza familiar de los métodos considerados, sino permaneciendo siempre empeñados en la busca de relaciones posibles, en toda dirección y a todo nivel.

4. Se ha dicho que el principio metodológico general no permite, al menos a primera vista, discriminación alguna entre filosofía y filosofía. Aun manteniendo la validez de esta aserción dentro de los límites establecidos en el parágrafo anterior, podemos ahora volver a considerarla, a ver si aquel principio contiene alguna indicación adecuada para subrayar la importancia de alguna técnica metódica particular o al menos de alguna familia de métodos. Es claro que si así fuese, esta técnica se recomendaría de modo especial a nuestra atención, y estaríamos autorizados para esperar de su uso resultados menos discutibles y más cercanos a la objetividad. Ahora bien, creo que del principio en cuestión puede sacarse alguna indicación de este género, si se parte de la presunción, fuertemente apoyada por los hechos, de que ningún método puede decirse perfecto e inmodificable (perfecto por inmodificable o inmodificable por perfecto), ya que uno de los resultados del uso de un método debe ser el de volver el método mismo más souple y al mismo tiempo más preciso, más extensible en sus aplicaciones, y más eficaz como instrumento de control de los resultados que permite conseguir. Mas en general podremos decir que el empeñarse en un método dado de investigación es también un empeñarse en aportar a este método las modificaciones que eventualmente exija el uso de él; y estos dos empeños son en realidad un solo empeño, ya que el empeñarse en un método no significa más que el uso efectivo de él, y el uso efectivo puede exigir en todo momento alguna modificación de él. Si un método encuentra, dentro del campo de investigaciones en que se lo emplea, dificultades debidas a elementos, hechos o condiciones surgentes en este campo, no puede continuarse usándolo, y por lo mismo se vuelve nulo el empeño de emplearlo, si no se modifica oportunamente el método mismo de modo que pueda hacer frente a las dificultades sobrevenidas. Puede suceder, empero, que el filósofo o los filósofos empeñados en el uso de este método prefieran, antes que modificarlo oportunamente, ignorar las dificultades que encuentra, y por ende hacer caso omiso de los elementos, los hechos o las condiciones de que surgen las dificultades. Pero esta escapatoria, aunque bastante frecuente, no puede considerarse como una alternativa razonable, y difícilmente puede proponerse como una regla en materia de metodología filosófica. Todo lo que puede decirse en esta 
materia es que hay filosofías que de hecho llevan a cabo, por las exigencias de su desarrollo, las modificaciones de su método, sin proponerse o prever por anticipado tales modificaciones. Y hay, en cambio, filosofías que admiten en derecho la modificabilidad de sus métodos y, por ende, incluyen en ellos y tratan de garantizar la posibilidad de la autocorrección de ellos. Para aducir algún ejemplo de clara significación, diré que la filosofía de Hegel es del primer tipo: con tanto como Hegel modificó su método desde la Fenomenología del Espiritu hasta la Enciclopedia, y al pasar de las primeras a las últimas categorías de la lógica, y de la lógica a la filosofía de la naturaleza y la filosofía del espíritu, la posibilidad de la corrección no forma parte del método mismo tal cual lo entendió y describió Hegel. Por otro lado, las filosofías llamadas empiristas pueden caracterizarse por el intento que hacen de incorporar a su método mismo la posibilidad de la autocorrección.

La posibilidad de la autocorrección define también los métodos de las disciplinas científicas, y esto establece el parentesco o al menos la afinidad y la simpatía entre el empirismo y la ciencia. Por ejemplo, el método de la observación experimental, de que se valen las ciencias de la naturaleza, comprende un número ilimitado de técnicas de las que cada una permite en todo instante controlar y volver a poner en tela de juicio los propios resultados; pero cada una de estas técnicas puede a su vez volver a controlarse y ponerse en tela de juicio, de suerte que se trata de garantizar la posibilidad de la corrección en cualquier dirección o nivel. Puede entonces decirse que el método de la observación experimental garantiza la posibilidad de la propia autocorrección.

Podemos en este punto darnos cuenta de la importante diferencia que hay entre la rectificación factual de un método (destino a que no se ha sustraído ninguno de los métodos conocidos) y la posibilidad de la rectificación que se hace valer como una exigencia del método. La primera es la modificación subrepticia del método propuesto, y las modificaciones en que consiste están hechas al azar y a capricho, resolviéndose siempre, en alguna medida, en un desmentir el método. La segunda, en cambio, no sólo permite, sino que exige la rectificación eventual del método y organiza el método mismo a los fines de esta rectificación. Tan sólo esta segunda vía hace posible un auténtico empeño metodológico, esto es, un empeño que no se encuentre en todo momento frente a la alternativa, o de desmentirse, o de la impotencia para operar en el campo mismo para el que se propuso. Podemos también añadir algo al principio metodológico general, y decir que no sólo empeña en el uso de técnicas de testimonio y de control, sino que exige, como regla, que sean susceptibles de autorrectificación.

5. Con esto he declarado las razones de mi simpatía por la dirección empirista del filosofar. Y las mismas razones indican que no debe entenderse 
el empirismo como una teoría acerca del origen del conocimiento, o como la pretensión de reducir el conocimiento a datos o elementos sensibles, sino más bien como un método, o mejor aún, como una exigencia metodológica. El problema del origen del conocimiento puede declararse ficticio; la posibilidad de reducir el conocimiento mismo a datos o elementos sensibles puede rechazares por quimérica; y con todo sigue siendo válida la exigencia que tiene en vista el empirismo. Este sólo puede caracterizarse eficazmente por el reconocimiento explícito (que se encuentra constantemente de nuevo en sus formas históricas) de que toda aserción debe estar sostenida por una técnica de testimonio y de control, y de que esta técnica debe ser susceptible de autorrectificación. En otras palabras, lo que define la orientación empirista en filosofía no es una tesis filosófica particular, o un complejo o sistema de resultados específicos, sino el reconocimiento explícito del principio metodológico general, y por lo mismo el estar dispuesto a utilizar, sin objeciones que prejuzguen, todo instrumento técnico que satisfaga el principio y todo resultado que pueda atestiguarse y controlarse con uno de tales instrumentos.

De aquí deriva la actitud que toma el empirismo frente a la ciencia, palabra por la que no sólo entiendo las ciencias naturales, sino también las disciplinas sociales, filológicas e históricas en cuanto están provistas de técnicas propias de testimonio y de control. La actitud empirista incluye el reconocimiento de la validez de la ciencia, y se vale de sus técnicas y de sus resultados pura y exclusivamente en la medida en que cada ciencia logra organizar eficazmente tales técnicas y, por ende, garantizar adecuadamente sus resultados. No puede ir más allá de la ciencia, en el sentido de atribuir a las técnicas y los resultados científicos un valor superior al que puede reconocérseles sobre la base de la eficacia de las técnicas, y por lo mismo en el grado de la garantía ofrecida a los resultados. No puede volverse jamás ciencismo, esto es, exaltación y dogmatización de la ciencia más allá de los límites de la validez que imponen sus técnicas, ya que es justo en los límites y en la rectificabilidad de estas técnicas en lo que está interesado el empirismo. La ciencia no puede ser para la orientación empirista un mito que empavesar o exaltar. En la ciencia, o más bien en las varias ciencias (porque no existe una ciencia única y total), no puede ver el empirismo más que complejos, más o menos organizados y coherentes, de técnicas más o menos eficaces para garantizar la validez de ciertas adquisiciones y para poner continuamente a prueba las adquisiciones mismas y las técnicas que las han proporcionado. Con esta actitud está, por tanto, conectado el sentido operante de los límites de las ciencias, de las imperfecciones de las técnicas y del carácter no dogmatizable de los resultados.

En este último rasgo debemos detenernos un momento. No está solo el empirismo en el utilizar los resultados de la investigación científica. Cualquier 
filosofía, incluso la más ajena al empirismo (piénsese, por ejemplo, en la de Hegel), utiliza o trata de incluir en sí una cierta suma de tales resultados, sea acogiéndolos directamente de las ciencias de su tiempo, sea recogiéndolos de la tradición filosófica y, por tanto, tomándolos en la forma elaborada por tal tradición. Este segundo caso es tan frecuente como el primero, y se traduce con mucha frecuencia en la presentación inconsciente de resultados científicos anticuados en la veste de "verdades absolutas" de naturaleza filosófica. Pero no es la recepción de los resultados de la ciencia lo importante a los fines de un correcto filosofar. Es importante, en cambio, la no-dogmatización de tales resultados: no dogmatización hecha sólo posible por considerar los resultados mismos en el contexto en que se obtuvieron, esto es, relativamente a las técnicas que los permitieron $\mathrm{y}$ a las posibilidades de modificar tales técnicas y de poner a discusión los resultados mismos. No es que se trate de resultados "provisionales", que sólo valgan, necesariamente, en el momento en que se consiguieron. No puede excluirse el que muchos o pocos de los resultados de la ciencia sean "definitivos", en el sentido de que puedan lograr superar victoriosamente el control de técnicas en continuo proceso de autorrectificación. Lo que debe excluirse es la petrificación dogmática de tales resultados, considerándolos arrancados de su contexto, fuera de los límites de validez permitidos por las operaciones de control y empleados como pedazos de materia bruta para construcciones de diversa naturaleza, a cuya solidez no pueden contribuir lo más mínimo. La polémica contra la "metafísica", $\tan$ frecuente en la tradición empirista, no es tan sólo la polémica contra métodos que se rehusan a permanecer abiertos al control (polémica conexa con el empeño metodológico mismo del empirismo), sino que es también la polémica contra el ciencismo inconsciente que no ignora la ciencia (o al menos la ciencia pasada), pero se vale de sus resultados a capricho, y esto es, sin tener en cuenta los procedimientos que en el seno de la ciencia los garantizan en alguna medida.

Que la filosofía pueda y deba estar dispuesta a utilizar los instrumentos técnicos y los resultados de las ciencias es cosa que no implica ni la pasividad de la filosofía frente a la ciencia, ni la reducción del dominio de la filosofía al dominio de la ciencia. No implica la pasividad, porque la utilización de la ciencia (dentro de los límites expuestos) por parte de la filosofía entra no sólo en el interés de la filosofía, sino también en el interés de las ciencias. Con urgencia y frecuencia cada vez mayores exigen hoy las ciencias (en especial las más ricamente desarrolladas) la intervención activa de la filosofía, no sólo sobre cuestiones metodológicas, sino también a ciertos niveles de su conceptuación y generalización (como, por ejemplo, para la formulación de las "teorías generales") y en ciertas zonas de colindancia o de interferencia entre disciplinas múltiples; las cuales, justo por su avanzada especialización, se hallan desprovistas de un terreno donde encontrarse para 
tratar los problemas que se presentan en esas zonas. No implica la reducción del dominio de la filosofía al de la ciencia, sea por la razón que acaba de decirse, sea porque ninguna ciencia, ni ningún complejo de ciencias puede proporcionar un motivo razonable para hacer tal reducción, $y$, menos que nada, puede proporcionarla la filosofía: la cual no puede a priori prescribirse zonas prohibidas, salvo por la reconocida imposibilidad de penetrar en esas zonas con las cautelas prescritas por el principio metodológico general.

6. Ahora bien, tal principio no nos ha indicado hasta ahora un método, sino tan sólo una familia de métodos, o, en otras palabras, ciertos caracteres generales y formales de los métodos que pueden escogerse y emplearse por una investigación filosófica abierta. Hasta este punto no resulta, por tanto, que tal principio pueda tomarse por fundamento de una elección exclusiva, esto es, de una elección que adopte una técnica particular de investigación con exclusión de todas las demás. Bien entendido, no estimo que esta situación sea nociva para la filosofía; ya que si el principio metodológico expresa el empeño fundamental del filósofo, sería extraño que empeñase al filósofo en empobrecer artificialmente el dominio de la filosofía, vedándole, con la prohibición de todos los métodos excepto uno, el acceso a regiones donde serían eficaces otros métodos; 0 , en otras palabras, lo empeñase en reducir la filosofía, de ese fecundo diálogo que ha sido por siglos, a un triste monólogo.

Pero si esto es verdad, también lo es, por las mismas razones, que cada filósofo debe practicar de buena fe la elección del método que le permite el trabajo más fecundo, y que esta elección sería mejor si el método elegido no tendiese a excluir todos los demás, sino que se mostrase convergente $o$ al menos compatible con otros. Mas esta compatibilidad y convergencia sólo pueden plantearse como problema y encaminarse así a la realización, si se llega a delinear un horizonte común en que diversas técnicas puedan encontrarse y mostrar su consonancia o disonancia así como el grado de su respectiva eficacia. ¿Es posible que el principio metodológico de que he hablado nos dé alguna indicación acerca de este horizonte?

El principio metodológico me empeña como filósofo (y también como no tilósofo) en dar cuenta humanamente de mis aserciones, esto es, en dar cuenta de ellas a los otros hombres ( $\mathrm{y}$ a mí mismo en tanto no quiera hacerme víctima de mis propios errores, ilusiones, falacias) mediante procedimientos que los otros (o yo mismo si quiero disminuir los peligros que acabo de mentar) puedan entender y emplear con una cierta eficacia. Por tanto, me coloca, desde el comienzo, en el horizonte humano, o más precisamente, en el horizonte de la intersubjetividad. Lo que negativamente exige de mí como filósofo es que renuncie a la pretensión de ser el ojo mismo del mundo o el supervisor divino del universo, el cual no debería, como es obvio, dar cuenta a nadie de la verdad que afirma o revela. Empeñándome en dar cuenta a los otros, el 
principio me empeña en considerarme a mí mismo constantemente en relación con los otros; por ende, a considerar las situaciones dispares, diversas, en contraste, en que me encuentro o puedo llegar a encontrarme como cualquier otro hombre.

En este punto podemos darnos cuenta de una segunda característica de la orientación empirista. Esta orientación, que en sus varias direcciones se ha valido de toda una "familia" de métodos, no sólo prescribe el uso de instrumentos de investigación rectificables, sino que también conduce a emplear tales instrumentos en el mundo humano. Las dos cosas están en conexión y podemos expresarlas con una sola fórmula, diciendo que el empirismo es el intento de explorar con ojos humanos el mundo humano.

Esto explica por qué el instrumento metódico fundamental del empirismo siempre ha sido el análisis, aun cuando se haya entendido y practicado (y continúe siéndolo) de diversos modos. Justo por fuerza de su empeño metodológico, está el empirismo vocado a analizar las situaciones humanas: no del hombre en general, en su esencia aislada y eterna, sino del hombre en esta o aquella situación, en las posibilidades efectivas, siempre limitadas y no siempre victoriosas, que le permite esta o aquella situación. Por eso ha insistido siempre también el empirismo en los límites del hombre. Estos límites le vienen al hombre de las condiciones que definen su situación en el mundo: las condiciones naturales y las histórico-sociales. "Límite" significa en efecto "condicionalidad"; y el análisis de las situaciones humanas es, bajo este punto de vista, el análisis de las condiciones que delimitan, esto es, definen y al mismo tiempo limitan las posibilidades efectivas de que dispone el hombre en un contexto más o menos importante de sucesos controlables.

La expresión "mundo humano" que he empleado para indicar el objeto propio de las técnicas de indagación que pueden (en el sentido antes señalado) llamarse "empiristas", exige algún esclarecimiento. En primer lugar, la palabra "mundo" no está tomada aquí como "totalidad absoluta", sino simplemente como el ámbito más o menos indeterminado de la convergencia, del encuentro o también del eventual conflicto de una familia de técnicas de investigación. Una técnica particular, si es suficientemente precisable, deslinda un campo de posibles investigaciones cuyo radio es más o menos extenso según el alcance de la técnica misma (por ejemplo, el campo de la física puede definirse por relación al alcance de los dos instrumentos fundamentales de esta ciencia, la regla de medir y el reloj). La noción de mundo designa, en su uso no dogmático (llamo "dogmático" el que experimentó la crítica de Kant), justo un conjunto de campos definidos por técnicas relativamente compatibles y en alguna medida convergentes. Podemos así hablar del "mundo natural" como del conjunto de campos cubiertos por las ciencias naturales en la medida en que las técnicas de éstas son relativamente compatibles y convergentes; o del "mundo histórico" como del conjunto de cam- 
pos en que pueden emplearse las técnicas de la investigación historiográfica, etc. El uso de la noción de mundo en este sentido restringido y específico implica otro corolario importante: el hombre, como "sujeto", esto es, como iniciador de la investigación y forjador de los instrumentos de ella, está ya, por este mismo hecho, en el mundo, en cuanto que su iniciativa cae desde el comienzo bajo el control de esas mismas condiciones a determinar las cuales se endereza la investigación. Lo que quiere decir, por ejemplo, que no puede hacerse física poniéndose fuera de las condiciones que limitan el uso de los instrumentos físicos (principio de indeterminación de Heisenberg); o que no puede hacerse historiografía poniéndose fuera de la historia, esto es, de aquellas condiciones que tiende a determinar la misma investigación historiográfica. El adjetivo "humano" que he empleado en la expresión susodicha, no indica la inclusión del mundo en el hombre o la naturaleza antropomórfica del mundo mismo, sino pura y exclusivamente esta relación de condicionamiento recíproco entre instrumentos y campos de investigación, relación por la cual se configura el campo de investigación como un "mundo" a medida que las operaciones de investigación consiguen éxitos extensos y perfeccionables.

7. Se ha dicho que el análisis es por excelencia el método de las filosofías de orientación empirista; y que, sin embargo, puede el análisis tomar formas y modos diversos. Puesto que hacer una lista y en seguida una crítica exhaustiva de estos modos y formas debe declararse quimérico si queremos permanecer dentro del horizonte empirista, me limitaré a aludir a las formas que ha tomado el análisis en la filosofía contemporánea.

En esta filosofía toma tres formas el apelar a un mundo como horizonte de investigaciones específicas: apelación a la experiencia, apelación al lenguaje vulgar, apelación a la existencia.

I) La apelación a la experiencia, propia del pragmatismo, es la apelación al uso del método experimental y a la riqueza y variedad de las situaciones humanas, que exigen la continua extensión y rectificación del método mismo. El pragmatismo ve en el método experimental sobre todo el instrumento adecuado para dar coherencia, orden y armonía a las situaciones humanas, por ende el instrumento de acción por excelencia en cuanto destinado a modificar tales situaciones. La debilidad del pragmatismo está en el dar por sentada la unidad de método, en el tomar como único método el de algunas disciplinas y en el reducir por ello todo tipo o forma de acción humana al ejercicio de este método.

2) La apelación al lenguaje vulgar, propia del neo-empirismo lógico, es la apelación a valerse del análisis del lenguaje corriente para el esclarecimiento de las situaciones humanas. $\mathrm{El}$ análisis que parte de las estructuras de una lengua determinada para llegar a las categorías, esto es, a los usos 
linguiísticos del lenguaje vulgar que se juzga expresan las situaciones comunes y recurrentes y están por ende en posibilidad de eliminar las confusiones y problemas ficticios y de lograr la aclaración crítica de las situaciones mismas. A este tipo de análisis, que tiene en cuenta el hecho de que el hombre es por excelencia un animal parlante, y que todas las técnicas de testimonio y de control en posesión suya están condicionadas en general por el lenguaje y en particular por usos lingüísticos determinados, no puede oponérsele ninguna objeción preconcebida. Debe, empero, observarse que esta técnica de análisis no puede considerarse como excluyente de todas las demás, ni agotando por sí sola la misión de la filosofía. Volveré dentro de un instante sobre este punto.

3) La apelación a la existencia, propia del existencialismo, es la apelación al análisis de las situaciones humanas consideradas como "fundamentales", o "esenciales", o "decisivas", o "situaciones-límites", etc., esto es, a las situaciones humanas más importantes, que menos se prestan a que se las eluda u olvide, como aquella por la cual el hombre tiene necesidades, o debe luchar, o debe morir, o debe vivir con los demás, etc., etc. El análisis de tales situaciones lo ha efectuado el existencialismo contemporáneo, si bien con diversas tonalidades, recurriendo constantemente al lenguaje vulgar y al científico, corregidos o completados con elementos sacados del lenguaje filosófico tradicional o excogitados y propuestos ad hoc. Bien que la apelación a la "existencia" obre análogamente a la apelación a la experiencia, como el memento de volver a poner a prueba los resultados y procedimientos del análisis existencial, este análisis presenta, sin embargo, el peligro de pretender que sus resultados brindan las estructuras "esenciales" y por lo mismo necesarias de las situaciones humanas, o sea tales que, una vez expuestas a la luz, se vuelve ocioso volver a controlarlas o ponerlas a discusión. El peligro de este tipo de análisis es, en otros términos, la petrificación metafísica, esto es, la trasformación subrepticia de adquisiciones analíticas en "verdades eternas" de viejo cuño.

Estos tres procedimientos analíticos no se encuentran necesariamente en relación de mutua exclusión, y si queremos ser fieles al empeño metodológico fundamental, puede y debe evitarse toda distorsión de ellos que conduzca a semejante petrificación exclusivista. Más precisamente, lo que exige la regla metodológica es que el problema particular que el filosofo encuentra delante de sí y se interesa por indagar, no quede artificialmente empobrecido y reducido a uno solo de los aspectos, y precisamente al que puede tratarse con la técnica analítica preferida. Consideremos, por ejemplo, el caso del problema de la moralidad entendido como problema de los caracteres y de las relaciones entre los hechos llamados "morales", o si se prefiere, de las funciones que tales hechos tienen en la vida individual y social del hombre. Entendido en este sentido, y esto es, dentro del horizonte empirista, no podrá, obviamente, afrontarse el problema moral con un discurso panegírico de la moral, o con la pretensión de establecer jerarquías de valores "absolutos" que proporcionen 
criterios necesarios de valoración. Se tratará más bien de comprender los hechos morales, esto es, de aclararlos en su significación, y por ello de percatarse de las funciones que lo que se llama "moral" tiene en las situaciones humanas comunes y recurrentes. Bajo este punto de vista, ofrecerá el problema moral varios aspectos. Será:

a) El problema de los significados de las expresiones morales del lenguaje corriente, esto es, de las reglas de uso de las proposiciones morales en tal lenguaje.

b) El problema de la estructura lógica de las proposiciones llamadas morales, o al menos en general de las proposiciones prescriptivas.

c) El problema de la disparidad de las valoraciones morales y, por ende, de la disparidad de uso de las proposiciones morales en grupos humanos a un mismo nivel o a diferente nivel de desarrollo, problema que debe examinarse sobre la base de observaciones sociológicas.

d) El problema de las relaciones entre moral y técnicas profesionales, entre moral y economía, entre moral y derecho, entre moral y religión, etc.

Es claro que cada uno de estos problemas o grupos de problemas exige poner por obra técnicas especiales de investigación, y por lo mismo la colaboración de investigadores de diversa procedencia que estén en posesión de tales técnicas. Pero es claro también que ninguno de estos problemas tomado por sí es el problema filosófico de la moral como se lo formuló antes, esto es, como problema de las características y de las funciones de la vida moral. Este problema está presente en todos y cada uno de los problemas que acaban de enunciarse, pero no es reducible a ninguno de ellos. Está, antes bien, situado en la zona de encuentro y eventualmente de conflicto entre las técnicas adecuadas para afrontar los problemas susodichos, y no es susceptible a su vez de que se lo afronte en su relativa integridad sino sobre la base de una hipótesis ad hoc de naturaleza filosófica que puedan confirmar o desmentir las técnicas particulares llamadas a juicio.

Este ejemplo, que no he escogido por azar, por encontrarme yo mismo empeñado en una investigación de tal género, puede servir al mismo tiempo como ilustración y como control del principio metodológico que he propuesto en el presente escrito.

Nicola Abbagnano

(trad. José Gaos) 